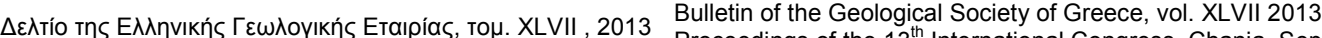

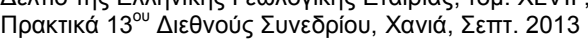

\title{
THE WEB PORTAL OF THE EUROSEISTEST STRONG GROUND MOTION DATABASE
}

\author{
Pitilakis K. ${ }^{1}$, Roumelioti Z. ${ }^{1}$, Manakou M. ${ }^{1}$, Raptakis D. ${ }^{1}$, Liakakis K. ${ }^{2}$, \\ Anastasiadis A. ${ }^{1}$ and Pitilakis D. ${ }^{1}$
}

\author{
${ }^{1}$ Research Unit of Soil Dynamics and Geotechnical Earthquake Engineering, Department of Civil \\ Engineering, Aristotle University of Thessaloniki, P.O. Box 424, 54124, Thessaloniki, Greece, \\ kpitilak@civil.auth.gr,zroum@auth.gr,manakou@civil.auth.gr,raptakis@civil.auth.gr, \\ anas@civil.auth.gr,dpitilak@civil.auth.gr \\ ${ }^{2}$ Department of Physics, Aristotle University of Thessaloniki, 54124 Thessaloniki, Greece, \\ kostas@physics.auth.gr
}

\begin{abstract}
Strong motion data that have been recorded during the 20-years of operation of the permanent network of EUROSEISTEST (Mygdonia basin, Northern Greece) have been homogenized and organized in an easily accessible, via the web, database. The EUROSEISTEST web portal and the application server running underneath are based solely on free and open source software (F/OSS; MySQL v5.5; RubyOnRails, $S A C$, Gnuplot and numerous GNU supporting utilities). Its interface allows the user to easily search strong motion data from approximately 200 events and 26 strong motion stations using event-related, record-related or station-related criteria. Further investigation of the data is possible in a graphical environment which includes plots of processed and unprocessed acceleration waveforms, velocity and displacement time histories, amplitude Fourier and response spectra and spectrograms. A great effort was directed toward the inclusion of accurate and most updated earthquake metadata, as well as a wealth of stations related information such as geotechnical and geophysical site characterization measurements, subsoil structure and site effects. Acceleration data can be easily downloaded in either SAC or ASCII format, while all stations metadata are also available to download.

Key words: subsoil structure, site effects, Mygdonia.
\end{abstract}

\section{Пєрí $\eta \psi \eta$}

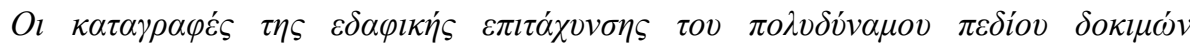

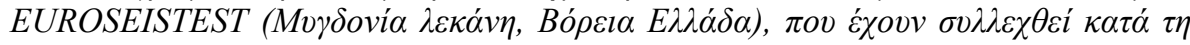



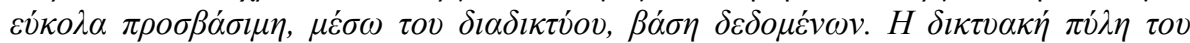

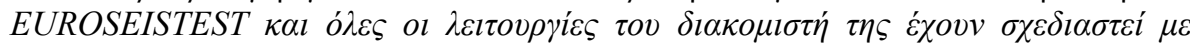

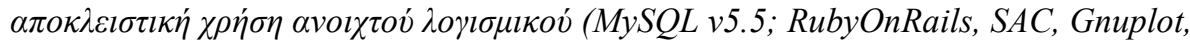

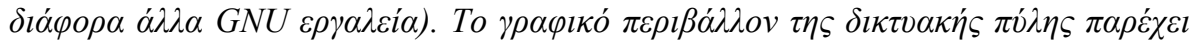

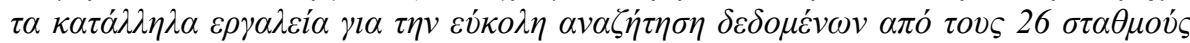

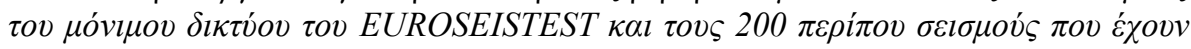

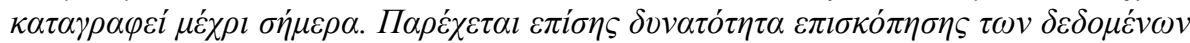

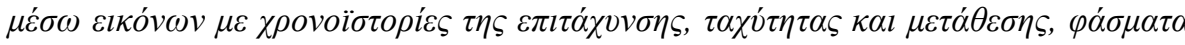

XLVII, No 3 - 1221 


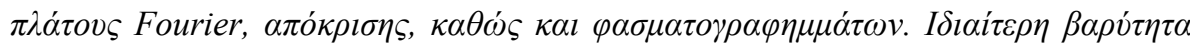

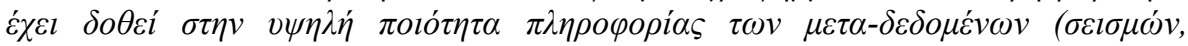

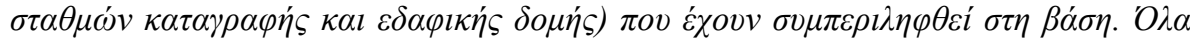

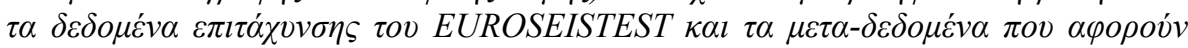

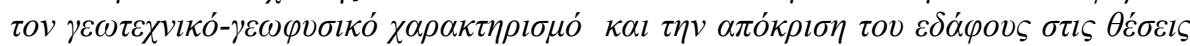

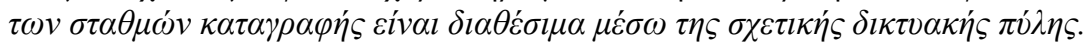

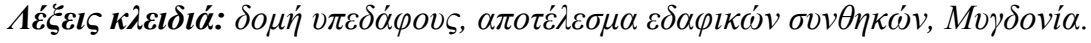

\section{Introduction}

EUROSEISTEST is a multidisciplinary European experimental site (e.g. Pitilakis et al., 2011) for integrated studies in earthquake engineering, engineering seismology, seismology, geotechnical engineering and soil dynamics. It is the longest running (for 20 years) basin-instrumentation project worldwide, and is located in the Mygdonia valley (epicentral area of the 1978, M6.4 earthquake), about $30 \mathrm{~km}$ to the NE of the city of Thessaloniki in northern Greece (Figure 1). It consists of a 3D accelerograph array and an instrumented single-degree-of-freedom structure (EuroProteas), the latter to be used in studies of soil foundation - structure interaction studies.

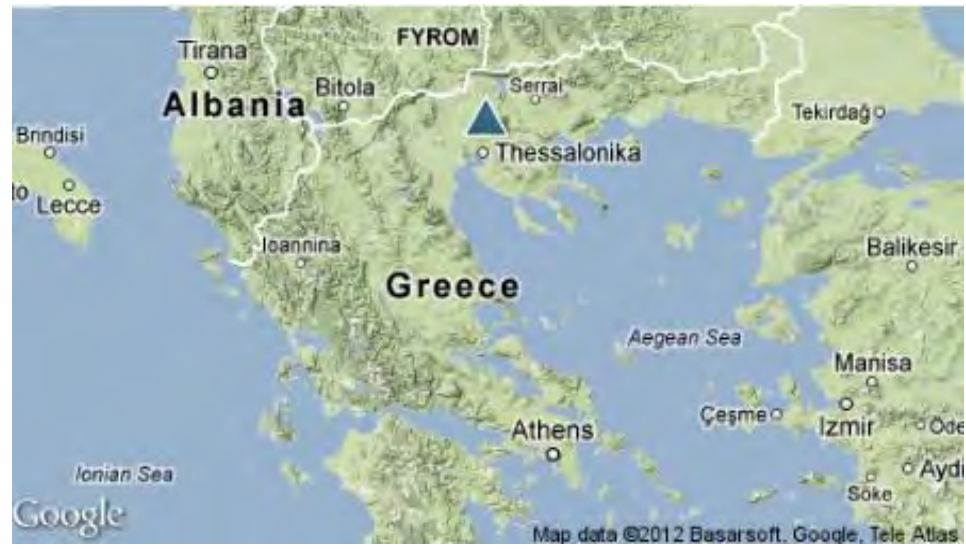

Figure 1 - Location (triangle) of the EUROSEISTEST experimental site.

The initial development of EUROSEISTEST was mainly funded by the European Commission Directorate General for Research and Development under the framework of consecutive EU research projects (EuroseisTest, 1993-1995; EuroseisMod, 1996-1999; Euroseisrisk, 2002-2005). In years after 2005, the maintenance and improvement of the array, as well as the construction of the EuroProteas structure, have been funded through resources of the Research Unit of Soil Dynamics and Geotechnical Earthquake Engineering (SDGEE, http://sdgee.civil.auth.gr) of the Aristotle University of Thessaloniki, as well as by several other European Union (e.g. SERIES, NERA) and international projects. The establishment and operation of the experimental site have been the responsibility of SDGEE with the contribution of the Institute of Engineering Seismology and Earthquake Engineering of the Earthquake Planning and Protection Organization of Greece (ITSAK-EPPO, http://www.itsak.gr), among other partners.

During its 20-years-long life, the permanent accelerograph network of EUROSEISTEST has recorded more than 190 events of local magnitude, $M_{L}$ in the range 1.5-6.6 and at epicentral distances from 1 to $500 \mathrm{~km}$. These events have provided circa 1000 three-component acceleration records, which along with stations and earthquakes metadata constitute a significant dataset, useful in different kinds of ground motion and site effects studies. These data and metadata were recently organized in a well-structured and easily extendable database, which is accessible through the internet at the web address http://euroseisdb.civil.auth.gr.

XLVII. No $3-1222$ 
In this paper, we present an overview of the EUROSEISTEST database web portal aiming to describe its fundamental functions and thus further facilitate the dissemination of our data.

\section{The Permanent Strong Motion Network of the EUROSEISTEST and its Database}

The permanent strong motion network of EUROSEISTEST was initially designed as a linear array of instruments along the small axis ( north-south direction) of the Mygdonia graben, between the villages of Profitis and Stivos. In 2003, another branch was added, this time along the long axis of the graben, thus oriented east-west. Overall, 26 strong motion stations have operated in the area since the establishment of the network in 1993. Today, the permanent network includes 21 modern strong motion accelerographs, 15 of which are located at the ground surface and 6 in down-hole arrays at the centre and at the northern edge of the instrumented area (Figure 2).
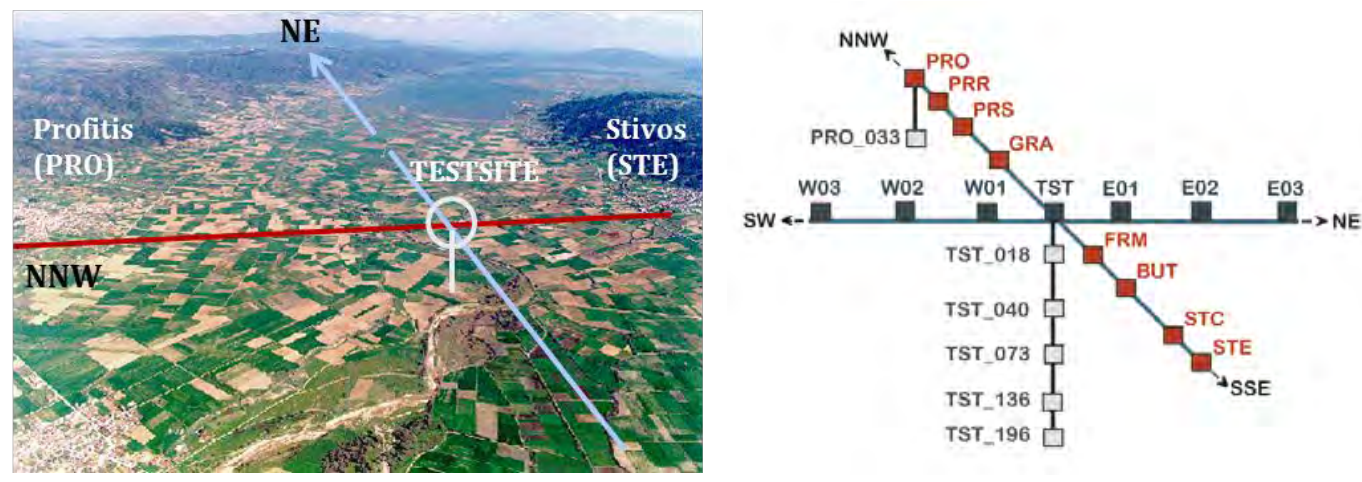

Figure 2 - The permanent accelerometric network of EUROSEISTEST. Left: Air photograph of the central part of the Mygdonia graben. The directions of the two branches of the surface array are noted as thick lines. The centre of the network (Test site) is the location of TST station and the deepest downhole array that reaches the underlying bedrock at circa 200m depth. Right: the current configuration of the EUROSEISTEST network with station codes.

Stations instrumentation has undergone many changes during the lifetime of the network. Initial installations included low resolution (12 and 16 bits) accelerographs without absolute timing (Global Positioning System, GPS). In 2003, when the east-west array was added, the entire network was upgraded with modern instruments of high resolution and GPS installed at all stations.

By the end of 2012, the network had recorded 190 events, which provided 997 three-component acceleration records. Most of the recorded events are from within and around the Mygdonia basin i.e. from epicentral distances, $R$, smaller than $50 \mathrm{~km}$ although the entire range of distances in the database is $1 \leq R \leq 500 \mathrm{~km}$. Magnitude distribution (local magnitude, $M_{L}$ ) of the events covers the range $1.5 \leq M_{L} \leq 6.6$.

\section{The Web Portal}

\subsection{Technical Information}

All components of the EUROSEISTEST web portal, including its database, have been built using solely Free/Open Source Software (F/OSS). The web server is using the NGINX platform, which combines high security standards with a friendly configuration scheme, increased functionality, robustness and smaller (compared to the more common Apache server) processing and memory requirements. Acceleration data and all accompanying stations and earthquakes metadata have 
been stored in a MySQL v5.5 relational database through a content management system (CMS), which has been built especially for our application. The background programming language is Ruby, combined with the well supported and very extensible web application framework called Rails (the combination often referred to as RubyonRails).

Part of the data processing is performed offline, mostly using the Seismic Analysis Code (SAC, Goldstein et al., 2003; Goldstein and Snoke, 2005). After the data upload through a user-friendly web interface, a second part of processing including data integration to velocity and displacement time histories, Fourier spectra and spectrograms computation, and production of the corresponding graphical plots, is taking place automatically. Several other pieces of F/OSS are used in this phase, notably SAC, GNUPLOT and other GNU utilities.

\subsection{Contents}

The EUROSEISTEST database web portal is hosted at the address: http://euroseisdb.civil.auth.gr. Its home page (Figure 3) includes basic information on the contents of the portal and a list of most recent announcements related to EUROSEISTEST in general and new event uploads to the web database. It also provides links to the major sections of the web portal, which are "The EUROSEISTEST", the "Database Search" and "SFSI" (Soil Foundation - Structure Interaction). Each section is described in the following.
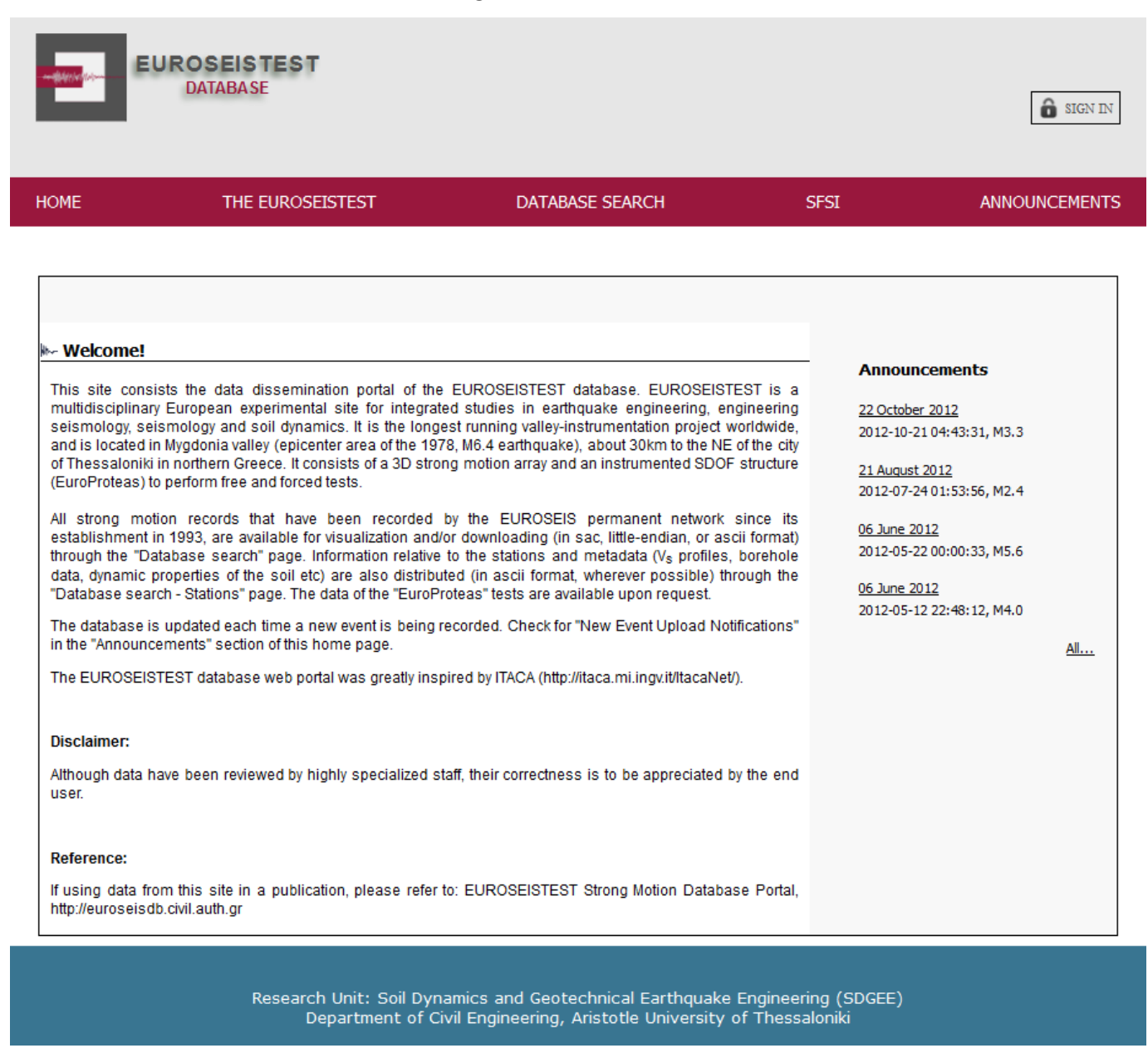

Figure 3 - The home page of the EUROSEISTEST web portal (http://euroseisdb.civil.auth.gr).

XLVII, No 3 - 1224 


\subsection{1. "The EUROSEISTEST" section}

This part of the EUROSEISTEST web portal is dedicated to the history of the test site and so far scientific achievements (Figure 4). More specifically, under this menu one can find information on:

- The establishment and operation status of the test site

- Its facilities

- The regional geology and tectonics

- The geotechnical/geophysical experiments and results that have taken place in the broader area since the establishment of the permanent accelerograph network (in 1993)

- A brief overview of the current knowledge of the 2D and 3D subsoil structure of the Mygdonia basin

- A full list of EUROSEISTEST-related scientific publications, etc.

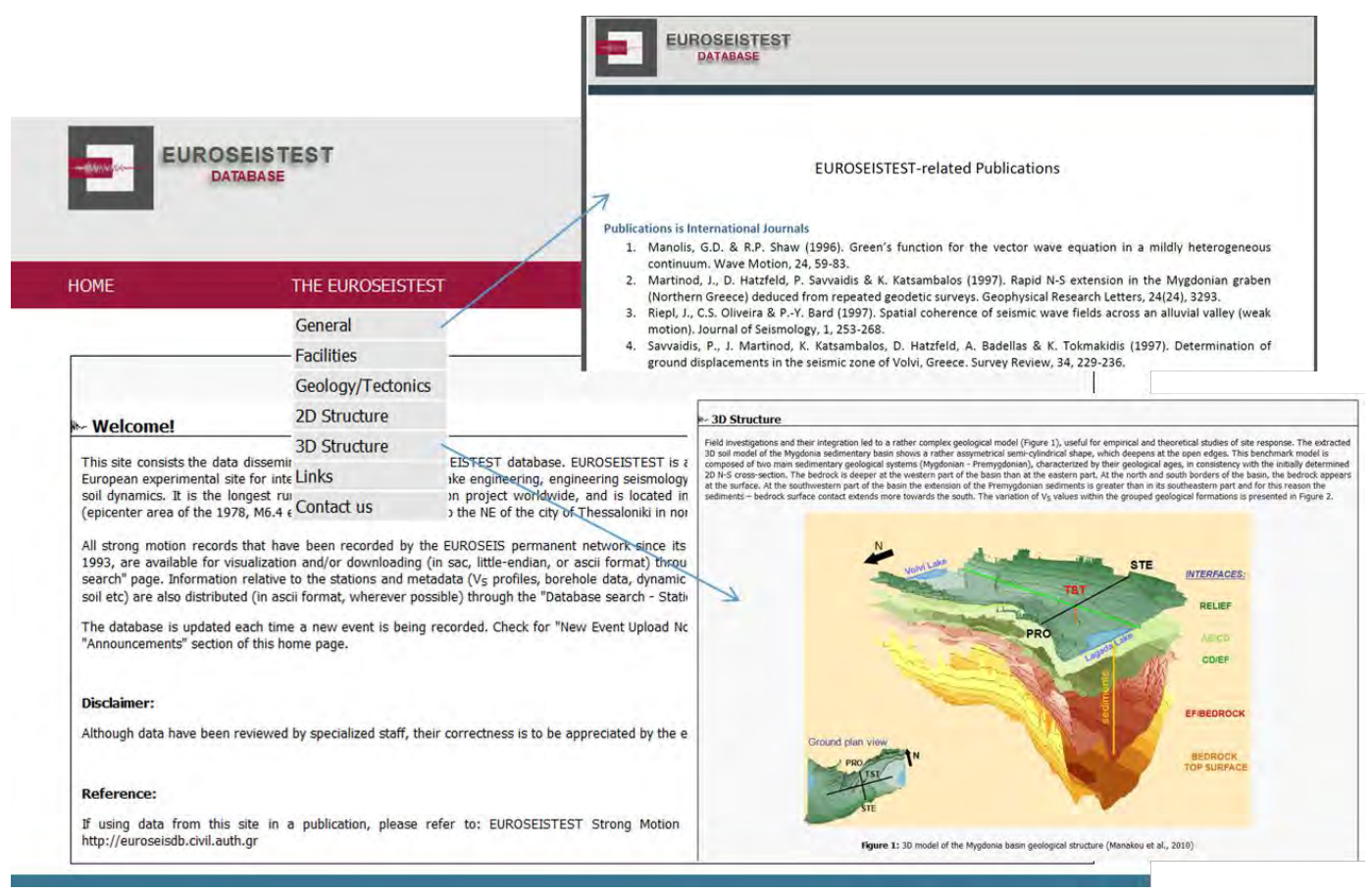

Figure 4 - Section of the web portal dedicated to the history of the test site and the so far scientific accomplishments.

\subsubsection{Database search}

The main section of the web portal is the one named "Database search". It constitutes an interface where the user can choose among several criteria to search the contents of the database (Figure 5). Following the common practice in other web-based acceleration databases (e.g. Pakor et al., 2011 and references therein), search criteria are grouped in record-related e.g. epicentral distance or peak ground acceleration, event-related e.g. the magnitude or the location of the earthquake and station-related e.g. soil category at the installation site. Query results are presented in the form of a table, on the same page, which provides links to several other sub-pages dedicated to either the requested station(s) or the requested event(s). 


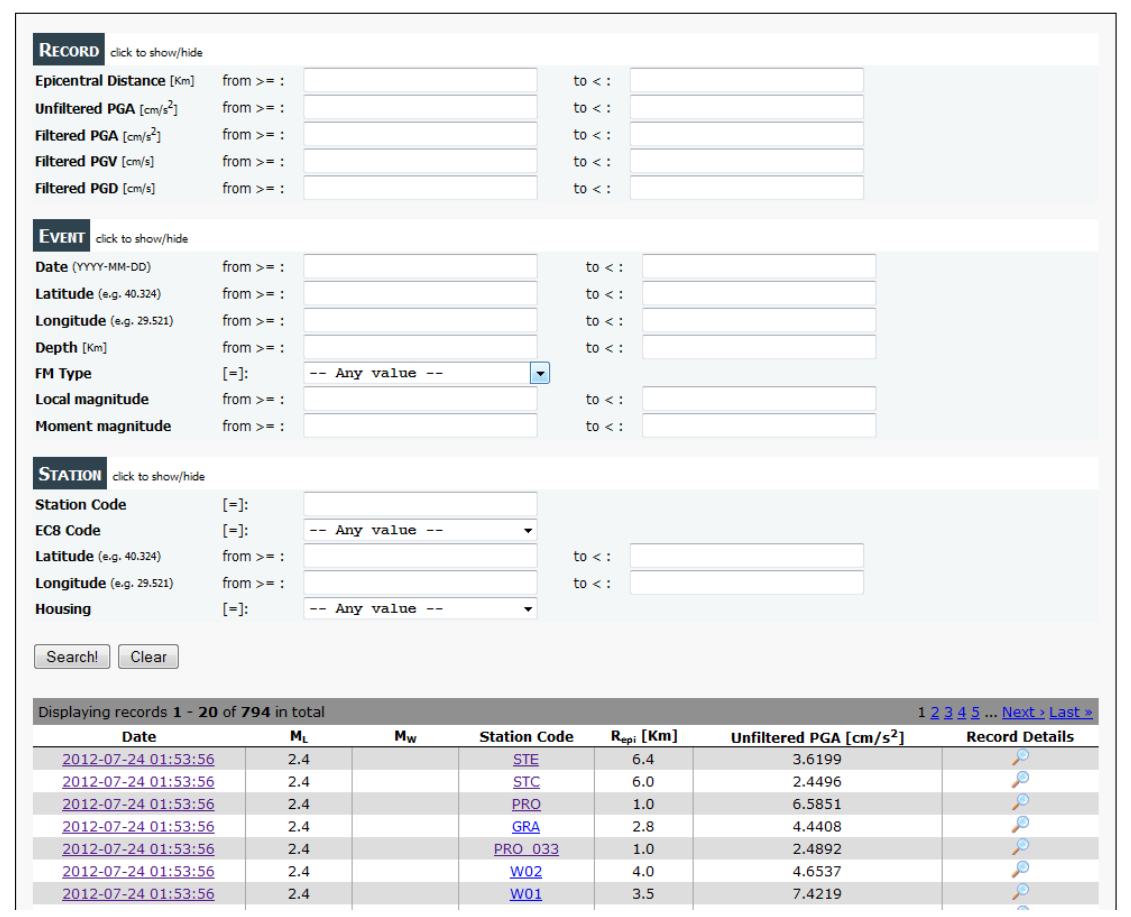

Figure 5 - Online form provided for searching the database contents. Three types of criteria related to the acceleration record, the earthquake event or the recording station can be used either individually or in combination. Query results are presented in the lower part of the web page in the form of a table.

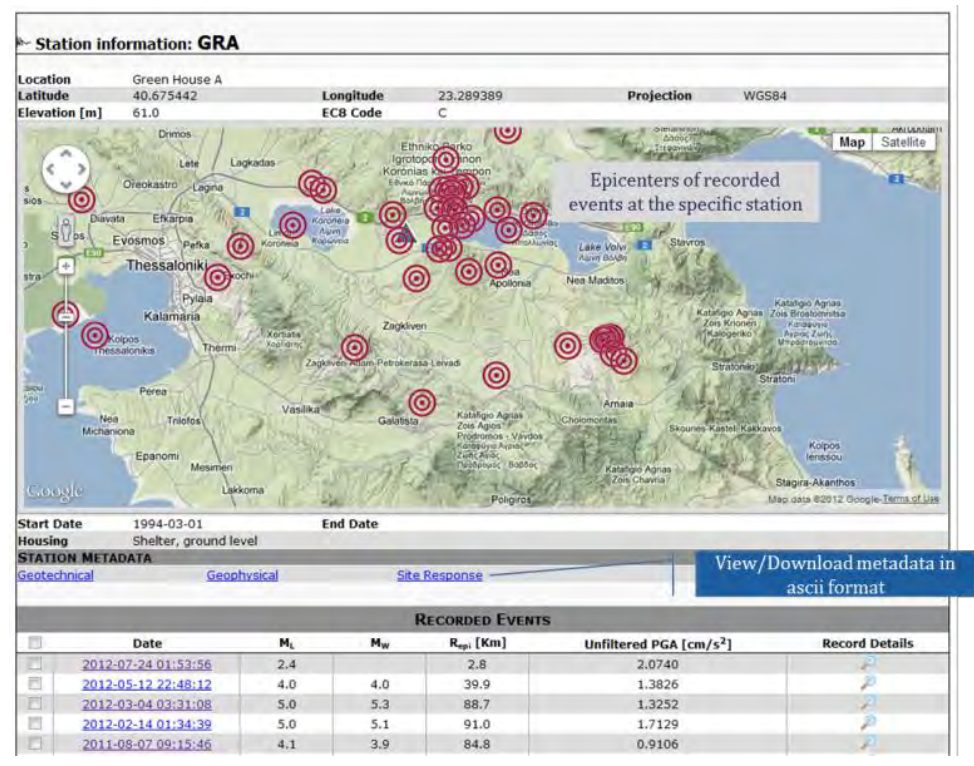

Figure 6 - Example of a station-dedicated web page. Includes all trivial information such as the location, housing, installation date etc., a Google map with the location of the station (triangle) and the epicentres of all events that have been recorded at the specific site, and links to different sets of station metadata.

XLVII, No 3 - 1226 
Station-dedicated web pages (Figure 6) include all trivial information such as the exact location (geographical coordinates and altitude/depth) of the installation site, the housing and the soil category characterization. It also includes a Google map showing the location of the station, as well as epicentres of all events that have been recorded at the specific site. Most importantly, it provides links to station metadata for the geotechnical and geophysical site characterization, as well as results on the site response with relative references (e.g. Jongmans et al., 1998; Raptakis et al., 2000, 2005; Manakou et al., 2010). It must be noted that all this information is available in both graphical and numerical formats and can be easily downloaded.

Event-dedicated web pages (Figure 7) provide basic metadata such as the location and focal mechanism of the event with relative references, a Google map (dynamic) showing the epicentre and the locations of stations that have recorded the specific earthquake, and a table with links to the actual records. At the bottom of the page there is a form for data downloading, where the user can choose the available data set(s) and download format(s). At present we provide two data formats (ascii and SAC, little endian) and three sets of acceleration data: raw, basically processed (mean, linear trends removal and units converted from counts) without any filtering, and filtered. The relevant response spectra are also available for download.

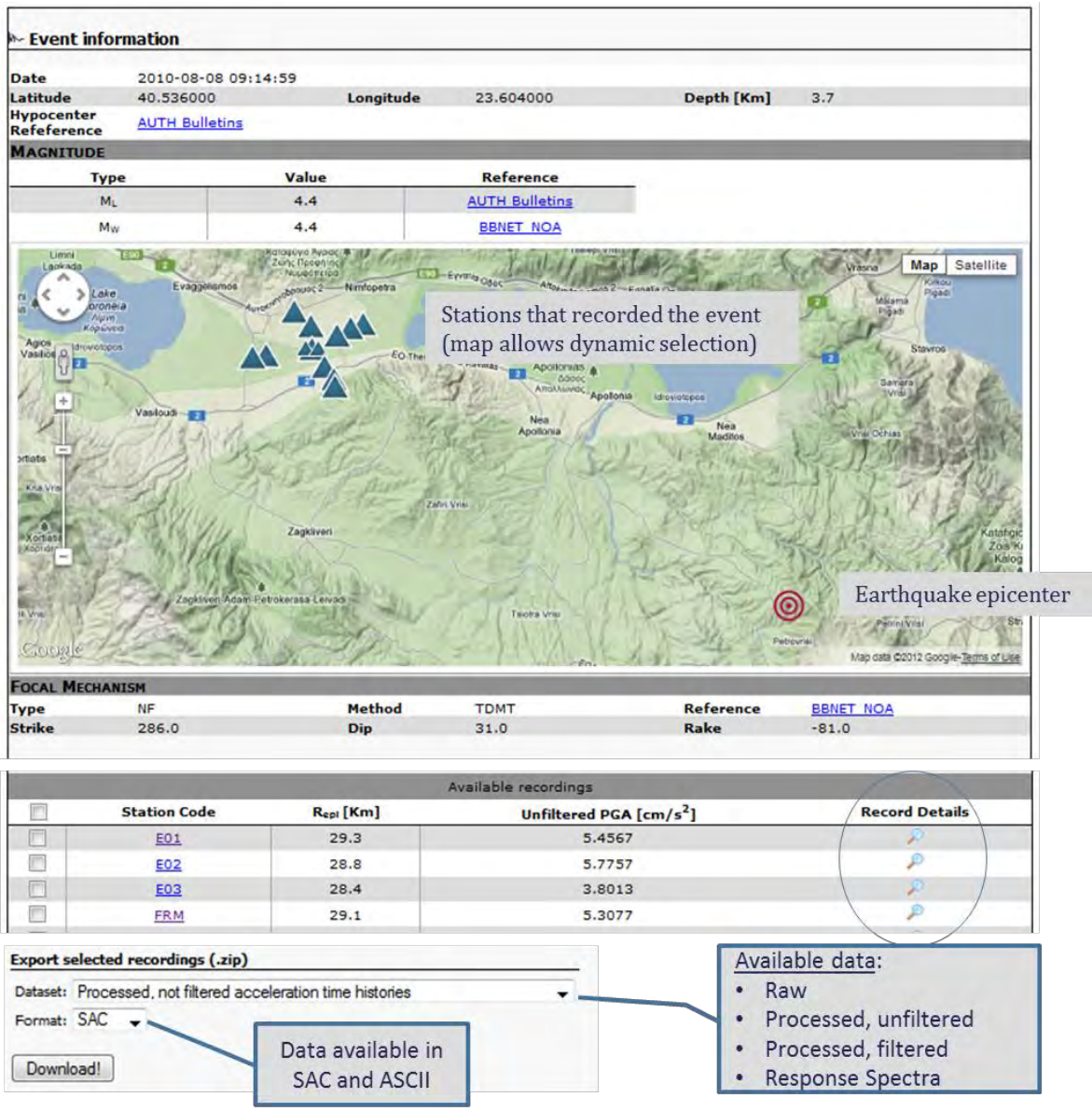

Figure 7 - Example of an event-dedicated web page. Apart from location and focal mechanism information, a map is provided with the locations of epicentre and recording stations. At the lower part of the web page a table summarizes parameters of the actual records and provides links (Record Details) to the corresponding waveforms. A form for facilitating data download is also included.

$\underline{\text { XLVII. No } 3-1227}$ 
If the user decides to further investigate the "record details" (Figures 5, 6, 7), he will find a group of plots for each recorded component of ground motion. An example of such plots is presented in Figure 8. These static graphs serve as a first screening of the quality of the data and basic characteristics of the ground motion e.g. peak values, duration, frequency content etc.
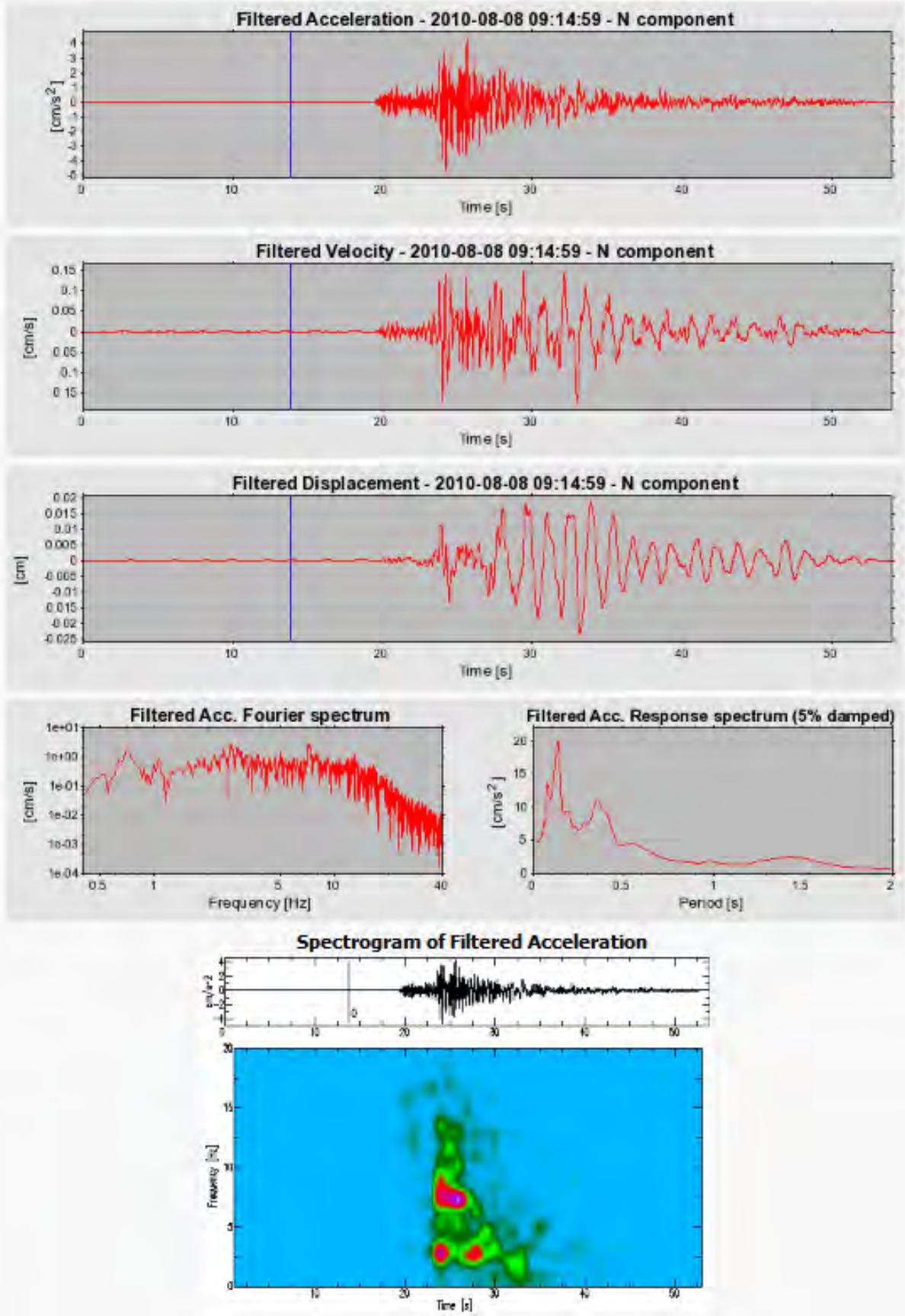

Figure 8 - Part of data plots available for a recorded component of acceleration. From top to bottom: acceleration, velocity and displacement time histories, Acceleration amplitude Fourier and response (5\% damped) spectra and spectrogram of the acceleration time history. 


\subsubsection{Soil - Foundation - Structure Interaction (SFSI)}

During the last few years, significant research effort in EUROSEISTEST is put on the topic of interaction between the soil, the foundation and the superstructure. Toward this research direction, EUROSEISTEST facilities were enriched with a large-scale prototype soil-foundation-structure system named "EuroProteas". EuroProteas conforms to the provisions of modern codes and regulations (e.g. Eurocode, EKOS2000, EAK2000) and has a simplified and reconfigurable structure in terms of mass and stiffness, designed to promote the effects of SFSI and wave propagation on the superstructure and in the soil.

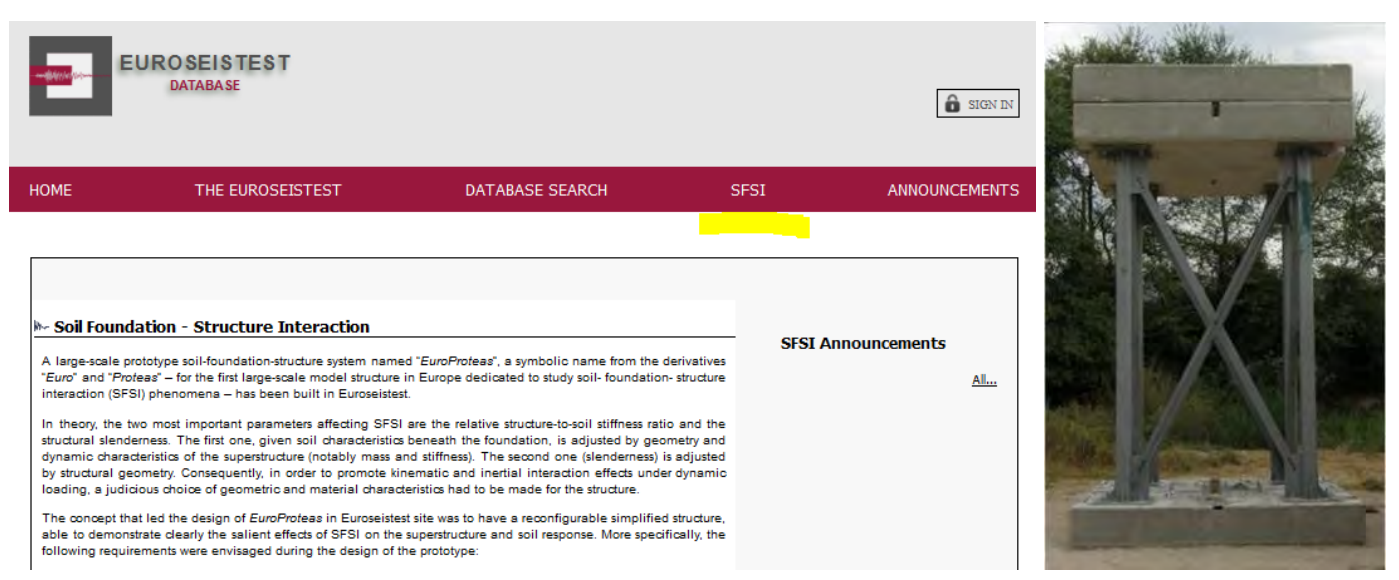

Figure 9 - Section of the web portal dedicated to the Soil Foundation - Structure Interaction (SFSI) research in EUROSEISTEST. Photo: EuroProteas, facility specially designed for SFSI studies.

The "SFSI" menu of the EUROSEISTEST web portal (Figure 9) has been designed to host information on EuroProteas and related experiments and scientific results. In the future, this section will be further extended to include a second database of data collected on EuroProteas during freevibration, forced-vibration and ambient noise experiments accounting for soil-foundation-structure interaction.

\section{Discussion}

The EUROSEISTEST experimental site has served for many years, most than any other similar test site in the world, the scientific community by providing high quality data for strong ground motion and site effect studies. Its data has already been used in more than 200 scientific publications, while its facilities have been used in many European and other international projects. One of the most significant advantages of this test site is the well-known subsoil structure, which makes it an ideal place to test/validate/verify methods and software for ground motion and site effects studies.

Through the EUROSEISTEST web portal we aim to facilitate further use of our dataset by an even larger number of scientists from around the globe. Toward this direction, we put our effort in the proper maintenance of all the existing facilities of EUROSEISTEST, but also in the continuous upgrade of the test site as a whole. A recent major addition has been the EuroProteas structural model, already present in the web portal in a dedicated section to SFSI studies. Data collected from dynamic vibration experiments on EuroProteas are, at the moment, available upon request, although in the near future relative datasets will be available through the EUROSEISTEST web portal. 
We intend to keep the EUROSEISTEST portal continuously updated by adding to its underlying database any newly recorded event. At present, such updates are performed within hours to few days after the earthquake occurrence. Scientists who are interested in being kept informed about EUROSEISTEST news and new event uploads can visit the "Announcements" section of the portal's home page or subscribe to the EUROSEISTEST mailing list in https://lists.auth.gr/sympa/ info/euroseisdb.

\section{Acknowledgments}

Thanks are due to Stavrina Kykalou, graphic designer of the Research Committee of the Aristotle University of Thessaloniki, for kindly helping us to improve the web portal's graphical environment. The overall design concept of the EUROSEISTEST database portal was greatly inspired by ITACA (Working group ITACA, 2010; Luzi et al., 2008), the Italian Accelerometric database. Finally, we would like to express our gratitude to all free/open source software developers that provided us with the tools to perform this work.

\section{References}

EAK 2000. National Greek Earthquake Design Code, Athens, Publication of Earthquake Planning and Protection Organization of Greece.

EKOS 2000. National Greek Reinforced Concrete Design Code, Athens, Publication of the Earthquake Planning and Protection Organization of Greece.

Goldstein P., Dodge D., Firpo M. and Minner Lee 2003. SAC2000: Signal processing and analysis tools for seismologists and engineers, Invited contribution to "The IASPEI International Handbook of Earthquake and Engineering Seismology", Edited by WHK Lee, H. Kanamori, P.C. Jennings, and C. Kisslinger, Academic Press, London.

Goldstein P. and Snoke A. 2005. SAC Availability for the IRIS Community, Incorporated Institutions for Seismology Data Management Center Electronic Newsletter.

Jongmans D., Pitilakis K., Demanet D., Raptakis D., Riepl J., Horrent C., Tsokas G., Lontzetidis K. and Bard P.-Y. 1998. Euroseistest: Determination of the Geological Structure of the Volvi Graben and Validation of the Basin Response to one Earthquake and one Shot, Bull. Seism. Soc. Am., 88(2), 473-487.

Luzi L., Hailemikael S., Bindi D., Pacor F., Mele F. and Sabetta F. 2008. ITACA (ITalian ACcelerometric Archive): A web portal for the dissemination of Italian strong-motion data, Seism. Res. Lett., 79, 716-722.

Pakor F., Paolucci R., Luzi L., Sabetta F., Spinelli A., Gorini A., Nicoletti M., Marcucci S., Filippi L. and Dolce M. 2011. Overview of the Italian strong motion database ITACA 1.0, Bull. Eq. Eng., 9, 1723-1739.

Pitilakis K., Raptakis D., Makra K., Manakou M. and Chávez-García F. J. 2011. Euroseistest 3D array for the study of complex site effects, in Earthquake Data in Engineering Seismology, Geotechnical, Geological, and Earthquake Engineering 14, S. Akkar et al. (eds), doi 10.1007/978-94-007-0152-6_11, Springer Science + Business Media B. V.

Raptakis D. G., Chavez-Garcia F., Makra, K. A. and Pitilakis K. D. 2000. Site Effects at Euroseistest-I. 2D Determination of the Valley Structure and Confrontation of the Observations with 1D Analysis, Soil Dyn. and Eq. Eng., 19(1), 1-22.

Raptakis D., Manakou M., Chávez-García, F. J., Makra K., and Pitilakis K. 2005. 3D configuration of Mygdonian basin and preliminary estimate of its site response, Soil Dyn. and Eq. Eng., 25, 871-887.

Manakou M. V., Raptakis D. G., Chávez-García F. J., Apostolidis P. I. and Pitilakis K. D. 2010. 3D soil structure of the Mygdonian basin for site response analysis, Soil Dyn. and Eq. Eng., 30(11), 1198-1211. 